Corrigendum

\title{
Corrigendum to "Renewal of Tidal Forests in Washington State after a Subduction Earthquake in A.D. 1700" [Quaternary Research, 56, 2, 139-147 (2001)]
}

Boyd E. Benson, Brian F. Atwater, David K. Yamaguchi, Lorin J. Amidon, Sarah L. Brown, Roger C. Lewis

The authors wish to point out that there is an error in the footnote on page 1 of this article. The corrected text should read: Supplementary data for this article (Tables A1-A3 and Figs. A1-A8) are available on IDEAL (http://www.idealibrary.com).

The Publisher would like to make readers aware that these supplementary data are now available via the HTML version of this article, at http://dx. doi.org/10.1006/qres.2001.2251. 